\title{
Pentraxin-Related Protein PTX3
}

National Cancer Institute

\section{Source}

National Cancer Institute. Pentraxin-Related Protein PTX3. NCI Thesaurus. Code C119682.

Pentraxin-related protein PTX3 (381 aa, 42 kDa) is encoded by the human PTX3 gene.

This protein is involved in both inflammation and complement recognition of pathogens. 